\title{
Thermal injury in tonsils and its relation to postoperative pain-a histopathological and clinical study
}

\author{
Mohammad Obeidat ${ }^{1,2^{*}}$ (D), Sónia Martins ${ }^{1,3}$, Ayat Aloqaily ${ }^{4,5}$, Margarida Santos ${ }^{1}$, Fátima Carneiro ${ }^{4,6,7}$ and \\ Jorge Spratley ${ }^{1,3,8}$
}

\begin{abstract}
Objectives: The aim of this study was to compare thermal injury and depth of necrosis of using different monopolar power settings in partial tonsillectomy and correlate the results with the postoperative pain score.

Results: The study included a total of 15 patients with mean of age of $5.7 \pm 2.57$ years. The mean depth of injury was significantly higher for the $25 \mathrm{~W}$ side $(0.973 \pm 0.613)$ versus the $15 \mathrm{~W}$ side $(0.553 \pm 0.218)(p=0.023)$. The postoperative pain score showed no significant differences between both sides.

Conclusion: The histopathologic depth of thermal injury is significantly higher with the $25 \mathrm{~W}$ monopolar microdissection in comparison to the $15 \mathrm{~W}$; however, it does not seem to correlate with the postoperative pain level. Apparently, power settings of $25 \mathrm{~W}$ can be safely used for pediatric intracapsular tonsillectomies, without added postoperative morbidity despite the deeper tissue injury observed in the tonsil.
\end{abstract}

Keywords: Intracapsular tonsillectomy, Pediatric tonsillectomy, Monopolar electrocautery, Thermal injury, Postoperative pain

\section{Background}

Tonsillectomy is one of the most common surgeries in children [1]. The usual indications to perform tonsillectomy can be divided into two main categories: recurrent tonsillitis and adenotonsillar hypertrophy causing airway obstruction and sleep-disordered breathing [2]. In recent years, intracapsular tonsillectomy (partial tonsillectomy) has emerged as an alternative surgical option to total tonsillectomy for OSA in children, with possible advantages related to lesser operative blood loss and postoperative pain [3-6]. Various techniques of tonsillectomy have been proposed, ranging from hot instrumentation as laser and monopolar cautery, mild thermal exposure

\footnotetext{
* Correspondence: mohdobeidat1985@gmail.com

'Department of Otorhinolaryngology, São João Hospital University Center,

Alameda Professor Hernani Monteiro, 4200-319 Porto, Portugal

${ }^{2}$ Department of Otolaryngology, Jordanian Royal Medical Services, Amman,

Jordan

Full list of author information is available at the end of the article
}

as coblation and radiofrequency, and cold techniques like the classic knife or powered instrumentation with a microdebrider [7]. Currently, monopolar electrocautery is still one of the most used techniques to perform intracapsular tonsillectomy mainly due to its wide availability and cost-effectiveness [8]. However, one of the possible drawbacks of this technique is the high heat generated, which may cause a significant tissue damage in the operated area and a subsequent increase in postoperative morbidity [9]. Therefore, the optimal power setting for dissection and hemostasis is controversial and some institutions recommend that surgeons use as little diathermy as possible [10].

Tissue thermal injury is a term used to define the direct and indirect tissue changes due to heat exposure. The pathophysiology of collateral tissue damage beyond the margins of excision is a wide field of research; also, the effect of acute thermal injury in variable types of tissues is still uncertain [11]. Very few studies have 
addressed the topic of thermal injury of the tonsillar lymphoid tissue [12], or its relation to postoperative pain score [13].

The aim of this study was to analyze the histopathological changes in tonsillar tissue, including depth of thermal injury and cellular changes in adjacent zones, and then to correlate it with the diathermy power setting used for dissection and the postoperative pain score.

\section{Methods}

This prospective, single-center study was conducted on a group of 15 pediatric patients between 2 and 12 years old who were admitted to São João University Hospital Center between January and March 2020. Patients with symptoms related to airway obstruction and sleepdisordered breathing were enrolled in the study. Children with chronic medical disease, craniofacial anomalies, congenital syndromes, and suspicion of malignancy were excluded. Intracapsular tonsillectomy using the monopolar electrocautery method with Colorado needle tip was performed for the patients using two different power settings bilaterally: 25 watts (W) on the right side (group A) and $15 \mathrm{~W}$ on the left side (group B).

All patients were prescribed the same analgesic protocol (oral paracetamol $15 \mathrm{mg} / \mathrm{kg}$ after $2 \mathrm{~h}$ of surgery). Postoperative pain was evaluated using the Wong-Baker face pain rating scale (WBFPRS) [14] $8 \mathrm{~h}$ after the surgery (day $0)$. Evaluation was done separately for each side: right side (group A) and left side (group B). Patients were also asked to compare pain between the two sides. Tonsillar specimens were sent for histopathological assessment in two separate containers (right tonsil and left tonsil) filled with $10 \%$ neutral buffered formalin. Several sections were sampled from each tonsil and were processed by paraffin embedding. Five-micron sections were cut and stained with hematoxylin and eosin. The histopathologist blindly assessed the pathologic findings in the tonsils, including inflammatory changes, signs of thermal tissue injury, and any possible signs of tissue damage beyond the necrotic line. At least three measurements for the deepest sites of thermal injury were taken for each sample, and the maximum one was recorded as the maximum depth of thermal injury (MDI). One specimen (from both sides; $15 \mathrm{~W}$ and $25 \mathrm{~W}$ ) was sent in glutaraldehyde for evaluation by both light and electron microscopy, specifically to examine signs of injury in the neighboring area beyond the cautery margin.

Comparisons of postoperative pain and depth of tissue injury were performed using the unpaired $t$-test. Statistical significance was accepted when the $p$-value was less than 0.05 .

Written consent forms were obtained from the legal guardians. The study was approved by the institutional medical ethical committee (reference number 58/2020).

\section{Results}

Fifteen children aged $2.5-12$ years (mean $5.7 \pm 2.57$ ) were included in the study. The male/female ratio was $6 / 4$. All children had a history of airway obstruction and sleep-disordered breathing.

Pain scores were obtained postoperatively, and from each side separately, using WBFPRS for 12 patients (three patients were less than 3 years old). The pain score mean is $4 \pm 2.14$ on both sides, ranging between 0 and 6 . There were no significant differences between the $15 \mathrm{~W}$ power setting side and the $25 \mathrm{~W}$ power setting side (Table 1).

Under light microscopic assessment, all tonsils showed florid reactive follicular hyperplasia and hypertrophy, with prominent germinal centers. Additionally, 20\% of cases displayed acute inflammatory cell infiltrate, cryptal microabscess formation with mild extension into the para-cryptal areas. The cauterized margin showed evidence of thermal injury in form of a superficial zone of tissue charring, destruction, and vacuolization. Deeper to this zone, other forms of thermal injury were seen including hemorrhage, destructed and occluded blood vessels, collagen fiber coagulation, and basophilia, in addition to tissue necrosis. The full thickness, of superficial and deep zones, of thermal injury was not uniform along the cautery margin but highly variable and was ranging between 0.1 and $1 \mathrm{~mm}$ on the $15 \mathrm{~W}$ side and between 0.1 and $2.5 \mathrm{~mm}$ on the $25 \mathrm{~W}$ side. Evaluating maximum depth of thermal injury (MDI) on both groups showed a mean of $0.973 \pm 0.613 \mathrm{~mm}$ for the $25 \mathrm{~W}$ group and $0.553 \pm 0.218 \mathrm{~mm}$ for the $15 \mathrm{~W}$ group (Fig. 1). The difference between both groups was statistically significant (Table 1).

Light microscopic assessment of the adjacent lymphoid tissue beyond the cautery margin showed subtle and indistinct changes, mainly in form of dilated lymphatics and tissue edema for both groups of tonsils. Detailed, higher resolution, examination for the closest $4 \mathrm{~mm}^{2}$ of neighboring lymphoid tissue to the cautery margin was also performed under electron microscopy to look for evidence of ultrastructural cellular damage. Assessment showed a predominantly intact and preserved tissue underneath the coagulated surface, without significant differences between the right and the left side. Both sides showed a similar rate of cell apoptosis (four per $\mathrm{mm}^{2}$ ), minimal

Table 1 Postoperative pain scores and maximum depth of injury for $15 \mathrm{~W}$ and $25 \mathrm{~W}$ monopolar electrocautery dissection

\begin{tabular}{llll}
\hline Power setting & $\mathbf{1 5} \mathbf{~ W}$ & $\mathbf{2 5 ~ W}$ & $\boldsymbol{p}$-value \\
\hline $\begin{array}{l}\text { Postoperative pain score } \\
\text { (mean } \pm \text { SD) }\end{array}$ & $4 \pm 2.14$ & $4 \pm 2.14$ & 1 \\
$\begin{array}{l}\text { Maximum depth of injury } \\
(\mathrm{mm}) \text { (mean } \pm \text { SD) }\end{array}$ & $0.553 \pm 0.218$ & $0.973 \pm 0.613$ & 0.023 \\
\hline
\end{tabular}



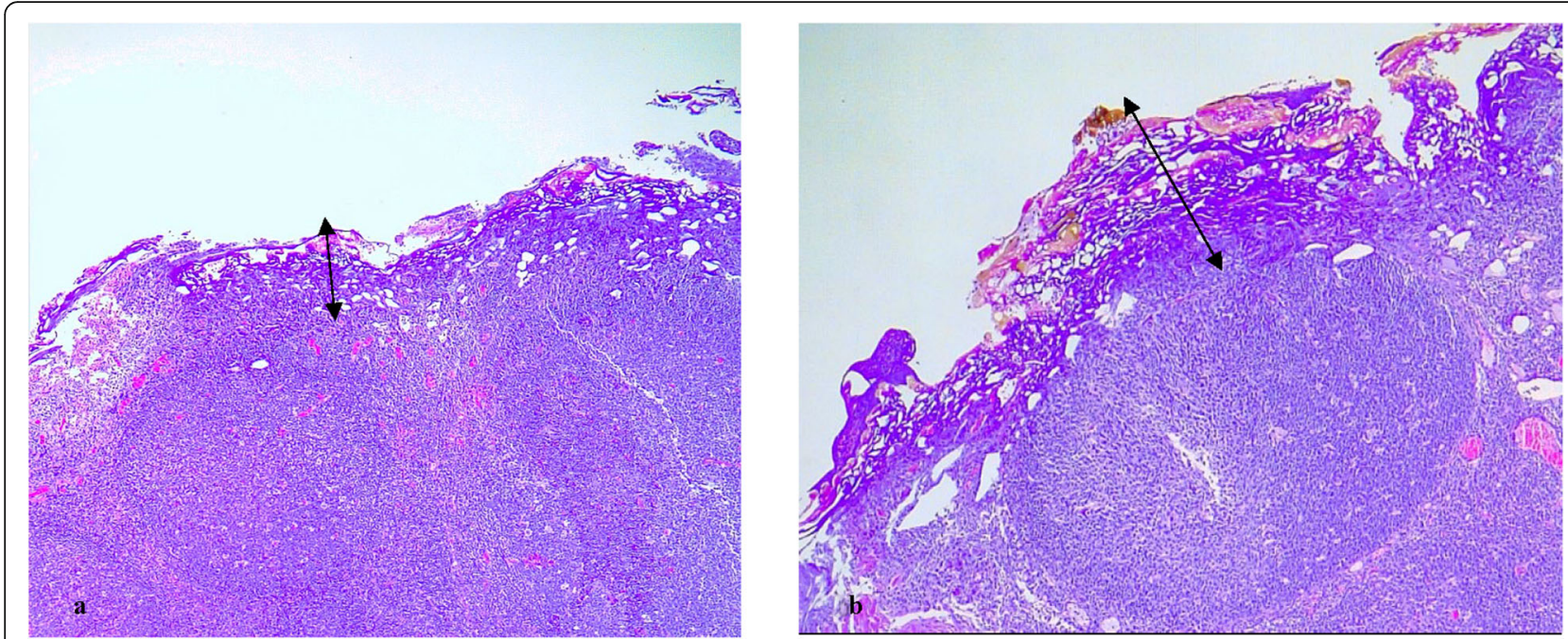

Fig. 1 Thermal injury under light microscopy. The zone of tissue charring, destruction, and vacuolization (double arrows) is more superficial on the $15 \mathrm{~W}$ side (a) in comparison to the $25 \mathrm{~W}$ side $(\mathbf{b})$ for the same patient $(\mathrm{H} \& \mathrm{E} ; \times 40)$

vacuolar cytoplasmic disintegration, and interstitial edema (Fig. 2).

\section{Discussion}

Postoperative pain remains the major drawback to tonsillectomy operations and the main cause for seeking outpatient medical attention in the first 2 weeks after surgery [15]. Several factors contribute to the level of postoperative pain including the patient's age, sex, indication of surgery, experience of the surgeon, and surgical technique [16]. Choosing a surgical technique seems to be the main modifiable factor that can affect the level of postoperative pain; therefore, various tools and techniques were developed and explored to find the most appropriate one. Cold dissection techniques have been associated with less pain in comparison to hot techniques, but in contrast, it has higher intraoperative blood loss and longer operative time [15]. In addition, performing partial (intracapsular) tonsillectomy has proven to be a viable and effective treatment and shown to reduce the severity and duration of pain [4].

Monopolar electrocautery is a widely available and commonly used hot technique in tonsillectomies [17], for many advantages related to its high efficiency, convenience, cost-effectiveness, low intraoperative bleeding rate, and short overall operative time [18, 19]. However, the electrical current that is used to cut, coagulate, and desiccate tissue through a significant generation of heat $\left(400-600{ }^{\circ} \mathrm{C}\right)[20,21]$ results in heat dissipation, which will lead to a collateral tissue damage and thermal injury
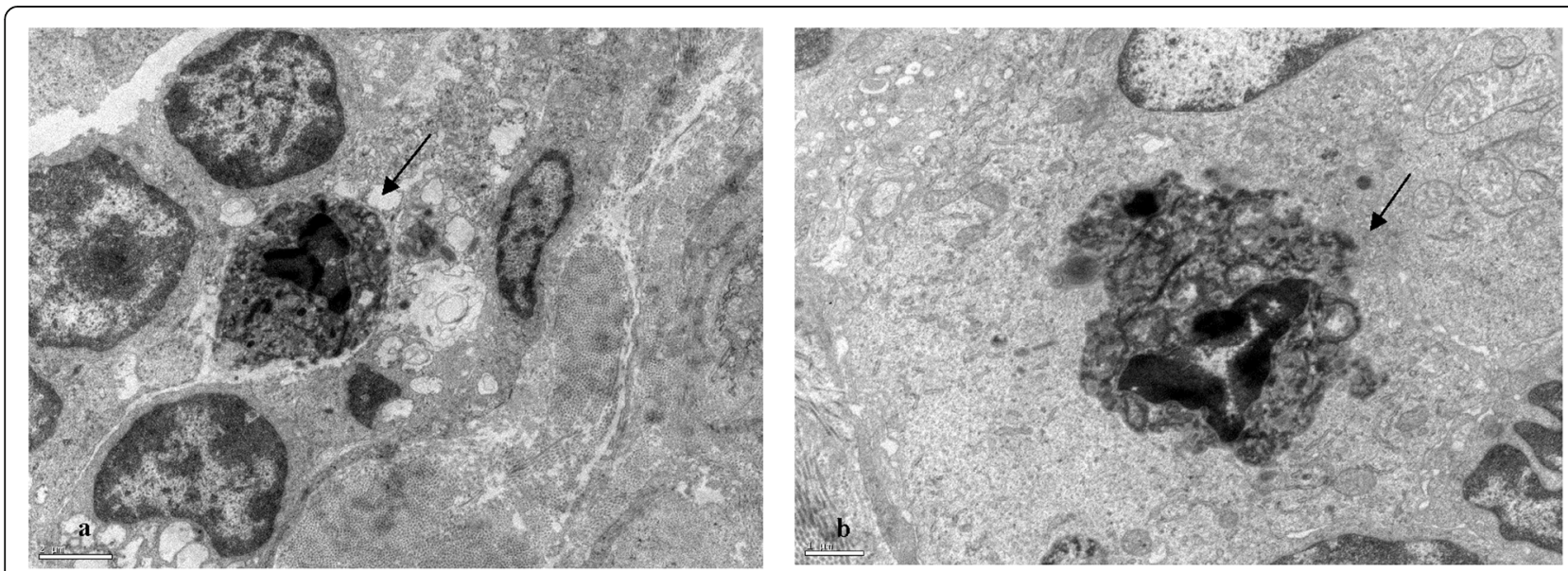

Fig. 2 In the tissue adjacent to the cautery margin, a few apoptotic bodies were identified (arrows) showing cellular shrinkage, chromatin condensation, fragmentation, and leaky nuclear envelopes. a Electron microscopy, $\times 8000$, on the 15 W side. b Electron microscopy, $\times 12000$, on the $25 \mathrm{~W}$ side 
in the neighboring tissue. The high-power intensity used in monopolar electrocautery and the consequently higher thermal injury produced at the residual tonsillar tissue and the surgical bed remains a major concern for surgeons and is usually linked to the higher postoperative pain in comparison to other methods [15]. To minimize this heat, a thinner needle tip, as the Colorado tip, was developed and used instead of the Bovie standard tip [22-24]. The finer electrocautery tip requires lower power and concentrates the electrical current to a smaller point [23], which results in lesser dissipation of energy into the surrounding tissues, causes smaller zone of tissue necrosis, and allows precise dissection [24, 25].

Another possible way to minimize the heat is through reducing the electrical current; however, there are no consensus or guidelines in respect of the optimal electrical power required during monopolar tonsillectomy. Some institutions also recommend that surgeons use as little diathermy as possible for dissection or hemostasis $[10,26]$, as it is believed to decrease thermal injuries to surrounding tissues and consequently postoperative pain. In our study, we chose to compare between two frequently used power settings in monopolar tonsillectomy procedures, the $25 \mathrm{~W}$ and the $15 \mathrm{~W}$. Since pain is a highly subjective symptom and harder to evaluate in pediatric patients, we designed our study to help the patients perform a comparative assessment of pain between the two sides and consequently minimize variability and subjectivity. In addition, we included patients with symptoms of airway obstruction and sleepdisordered breathing exclusively to eliminate pain variation related to different surgical indications. The different power settings, however, showed no significant difference in postoperative WBFPRS scores at the time of discharge (day 0). A single previous study had also compared the visual analogue scale (VAS) pain scores after tonsillectomies between two groups of adult patients (46 patients each) using $15 \mathrm{~W}$ for one group and $25 \mathrm{~W}$ for the other [10]. Group pain scores were obtained at 5 days postoperatively and it was slightly higher in the $15 \mathrm{~W}$ group in 4 days (days $1,5,7$, and 14), while it was slightly higher in the $25 \mathrm{~W}$ group in 1 day (day 3 ), but all differences were not statistically significant. Although the results were not significant, it surprisingly indicates that the $15 \mathrm{~W}$ group may have higher pain scores for the follow-up period. In addition, they concluded that power settings have no different degree of primary or secondary hemorrhage. The $25 \mathrm{~W}$ group had a significantly shorter mean operation time (by 5.1-min difference) and a significantly lower minimal hemorrhage rate. Although the difference was significant for the minimal bleeding only (less than $10 \mathrm{ml}$ ), this type of bleeding can lead to uncomfortable healing process and poor patient and caregiver satisfaction [10].
Signs of histopathologic injury caused by various surgical techniques have been studied through animal model experiments and demonstrated a significant association between surgical techniques, tissue injury level, and wound healing time [20, 24]. In humans, the alternative approach was to study the extent of thermal injury in the removed part of the tonsil in tonsillectomy samples. This approach has its limitations, since the level of injury in the removed part will not be an exact mirror image of that at the site of surgery, due to the ongoing healing process and development of features of chronic inflammation at the wound site. However, it will provide a considerable clue to the injury level at the wound site [13, 27, 28]. Many studies used this approach as part of the assessment of new techniques used in tonsillectomies. Generally, results showed that the degree of histopathologic thermal injury significantly correlates with postoperative morbidity and pain scores when comparing different techniques. For example, Magdy et al. [27] found that the coblation technique inflicted significantly less thermal tissue injury than either electrocautery or laser and offered significant advantages in terms of postoperative pain and healing. Another study showed that the plasma blade technique had a significantly lower MDI and lower visual analogue scale (VAS) score in comparison to the bipolar radiofrequency clamp technique [13]. In addition, in pediatric tonsillectomies, the molecular resonance technique resulted in significantly reduced histopathologic thermal injury and lower pain scores in comparison to the coblation technique, which was reflected in reduced medication requirements [29]. In our study, the MDI was investigated for two different power settings, $15 \mathrm{~W}$ and 25 $\mathrm{W}$, using the same monopolar electrocautery technique. The difference in MDI was significant; however, it was not large enough to affect the postoperative level of pain and WBFPRS score. In addition, it did not affect the degree of collateral tissue damage for the closest zone to the cautery margin. For both power settings, the assessment under electron microscopy demonstrated very mild, subtle, and equivalent changes. This comparable level of collateral tissue injury and postoperative pain indicates similar levels of safety between the studied power settings.

Limitations of this study included the presence of multiple surgeons, the subjective assessment of pain, assessing pain in day 0 only, and the small number of samples that were studied in this series.

\section{Conclusion}

The histopathologic depth of thermal injury is significantly higher with the $25 \mathrm{~W}$ monopolar microdissection in comparison to the $15 \mathrm{~W}$; however, it does not correlate with the postoperative pain level or tissue injury beyond the line of cautery. Twenty-five-watt power intensity can be safely used for pediatric tonsillectomies, without increased morbidity to the child. 


\section{Abbreviations}

WBFPRS: Wong-Baker face pain rating scale; MDI: Maximum depth of thermal injury; W: Watt

\section{Acknowledgements}

The authors are grateful to the Histology and Electron Microscopy Service (HEMS) team at the i3S (Institute for Research and Innovation in Health, University of Porto) for providing the necessary equipment and the technical support for the electron microscopic analysis.

\section{Authors' contributions}

$\mathrm{MO}$ and JS conceived of the presented idea and participated in writing the manuscript draft, MO collected and analyzed the data, JS supervised and coordinated the work between clinicians and histopathologists, SM obtained consent forms from patient's guardians, SM and MG helped in analyzing the data and obtaining the medical records from data system, MS prepared and selected the samples of the study, AA analyzed and wrote the histopathology reports and participated in writing the manuscript, and FC prepared the lab to receive tissue samples and helped in collecting histopathology reports. All authors have read and approved the manuscript.

\section{Funding}

None

\section{Availability of data and materials}

The records and data of samples which include the names and procedures and the histopathological reports and pain scores are available in an Excel file and will be provided upon request.

\section{Declarations}

\section{Ethics approval and consent to participate}

Written consent forms were obtained from the legal guardians. The study was approved by the institutional medical ethical committee in Sao Joao Hospital University Center (reference number 58/2020).

\section{Consent for publication}

Not applicable

\section{Competing interests}

The authors declare that they have no competing interests.

\section{Author details}

'Department of Otorhinolaryngology, São João Hospital University Center, Alameda Professor Hernani Monteiro, 4200-319 Porto, Portugal. ${ }^{2}$ Department of Otolaryngology, Jordanian Royal Medical Services, Amman, Jordan. ${ }^{3}$ Unit of Otorhinolaryngology, Department of Surgery and Physiology, University of Porto Faculty of Medicine, Porto, Portugal. ${ }^{4}$ Ipatimup Diagnostics, Institute of Molecular Pathology and Immunology, University of Porto (IPATIMUP)/i3S, Porto, Portugal. ${ }^{5}$ Department of Clinical Pathology, King Abdullah University Hospital (KAUH), Jordan University of Science and Technology (JUST), Irbid, Jordan. ${ }^{6}$ Department of Pathology, São João Hospital University Center, Porto, Portugal. ${ }^{7}$ Department of Pathology and Oncology, Faculty of Medicine, University of Porto, Porto, Portugal. ${ }^{8}$ Center for Health Technology and Services Research (CINTESIS), Porto, Portugal.

\section{Received: 8 October 2020 Accepted: 18 March 2021}

\section{Published online: 10 May 2021}

\section{References}

1. Mitchell RB, Archer SM, Ishman SL, Rosenfeld RM, Coles S, Finestone SA, Friedman NR, Giordano T, Hildrew DM, Kim TW, Lloyd RM, Parikh SR, Shulman ST, Walner DL, Walsh SA, Nnacheta LC (2019) Clinical practice guideline: tonsillectomy in children (update)-executive summary. Otolaryngol Head Neck Surg. 160(2):187-205. https://doi.org/10.1177/0194 599818807917

2. Sumilo D, Nichols L, Ryan R, Marshall T (2019) Incidence of indications for tonsillectomy and frequency of evidence-based surgery: a 12-year retrospective cohort study of primary care electronic records. Br J Gen Pract. 69(678):e33-e41. https://doi.org/10.3399/bjgp18X699833
3. Sathe N, Chinnadurai S, McPheeters M, Francis DO (2017) Comparative effectiveness of partial versus total tonsillectomy in children. Otolaryngol Head Neck Surg. 156(3):456-463. https://doi.org/10.1177/01 94599816683916

4. Kim JS, Kwon SH, Lee EJ, Yoon YJ (2017) Can intracapsular tonsillectomy be an alternative to classical tonsillectomy? A meta-analysis. Otolaryngol Head Neck Surg. 157(2):178-189. https://doi.org/10.1177/0194599817700374

5. Junaid M, Sood S, Walijee H, Dorgham J, De S (2019) Pain scores and recovery post tonsillectomy: intracapsular versus extracapsular coblation. J Laryngol Otol. 133(9):775-781. https://doi.org/10.1017/S0022215119001610

6. Koltai PJ, Solares CA, Koempel JA, Hirose K, Abelson TI, Krakovitz PR, Chan J, Xu M, Mascha EJ (2003) Intracapsular tonsillar reduction (partial tonsillectomy): reviving a historical procedure for obstructive sleep disordered breathing in children. Otolaryngol Head Neck Surg. 129(5):532538. https://doi.org/10.1016/S0194-5998(03)00727-7

7. Verma R, Verma RR, Verma RR (2017) Tonsillectomy-comparative study of various techniques and changing trend. Indian J Otolaryngol Head Neck Surg. 69(4):549-558. https://doi.org/10.1007/s12070-017-1190-6

8. D'Eredita R (2010) Tonsillectomy in children: a five-factor analysis among three techniques-reporting upon clinical results, anesthesia time, surgery time, bleeding, and cost. Laryngoscope. 120(12):2502-2507. https://doi.org/1 0.1002/lary.21128

9. Nunez DA, Provan J, Crawford M (2000) Postoperative tonsillectomy pain in pediatric patients: electrocautery (hot) vs cold dissection and snare tonsillectomy--a randomized trial. Arch Otolaryngol Head Neck Surg. 126(7): 837-841. https://doi.org/10.1001/archotol.126.7.837

10. Baek MK, Kim YS, Choi SH, Woo JH, Lee JH, Kim DY (2016) A pilot randomized comparative study of two diathermy power settings for monopolar microdissection and bipolar hemostasis during tonsillectomy. Korean J Otorhinolaryngol -Head and Neck Surg. 59(12):836-842. https://doi. org/10.3342/kjorl-hns.2016.59.12.836

11. Purschke M, Laubach HJ, Anderson RR, Manstein D (2010) Thermal injury causes DNA damage and lethality in unheated surrounding cells: active thermal bystander effect. J Invest Dermatol. 130(1):86-92. https://doi.org/1 0.1038/jid.2009.205

12. Modi VK, Monforte H, Geller KA, Koempel JA (2009) Histologic assessment of thermal injury to tonsillectomy specimens: a comparison of electrocautery, coblation, harmonic scalpel, and tonsillotome. Laryngoscope. 119(11):22482251. https://doi.org/10.1002/lary.20612

13. Bogrul MF, Unal A, Yilmaz F, Sancaktar ME, Bakirtas M (2019) Comparison of two modern and conventional tonsillectomy techniques in terms of postoperative pain and collateral tissue damage. Eur Arch Otorhinolaryngol. 276(7):2061-2067. https://doi.org/10.1007/s00405-019-05464-y

14. Tomlinson D, von Baeyer CL, Stinson JN, Sung L (2010) A systematic review of faces scales for the self-report of pain intensity in children. Pediatrics. 126(5):e1 168-e1198. https://doi.org/10.1542/peds.2010-1609

15. Leinbach RF, Markwell SJ, Colliver JA, Lin SY (2003) Hot versus cold tonsillectomy: a systematic review of the literature. Otolaryngol Head Neck Surg. 129(4):360-364. https://doi.org/10.1016/S0194-5998(03)00729-0

16. Elinder K, Soderman AC, Stalfors J, Knutsson J (2016) Factors influencing morbidity after paediatric tonsillectomy: a study of 18,712 patients in the National Tonsil Surgery Register in Sweden. Eur Arch Otorhinolaryngol. 273(8):2249-2256. https://doi.org/10.1007/s00405-016-4001-x

17. Walner DL, Parker NP, Miller RP (2007) Past and present instrument use in pediatric adenotonsillectomy. Otolaryngol Head Neck Surg. 137(1):49-53. https://doi.org/10.1016/j.otohns.2007.02.036

18. Weimert TA, Babyak JW, Richter HJ (1990) Electrodissection tonsillectomy. Arch Otolaryngol Head Neck Surg. 116(2):186-188. https://doi.org/10.1001/a rchotol.1990.01870020062016

19. Wexler DB (1996) Recovery after tonsillectomy: electrodissection vs. sharp dissection techniques. Otolaryngol Head Neck Surg. 114(4):576-581. https:// doi.org/10.1016/S0194-5998(96)70249-8

20. Chinpairoj S, Feldman MD, Saunders JC, Thaler ER (2001) A comparison of monopolar electrosurgery to a new multipolar electrosurgical system in a rat model. Laryngoscope. 111(2):213-217. https://doi.org/10.1097/0000553 7-200102000-00005

21. Vilos GA, Rajakumar C (2013) Electrosurgical generators and monopolar and bipolar electrosurgery. J Minim Invasive Gynecol. 20(3):279-287. https://doi. org/10.1016/j.jmig.2013.02.013

22. Al-Qahtani AS (2012) Post-tonsillectomy hemorrhage. Monopolar microdissection needle versus cold dissection. Saudi Med J. 33(1):50-54 
23. Perkins J, Dahiya R (2003) Microdissection needle tonsillectomy and postoperative pain: a pilot study. Arch Otolaryngol Head Neck Surg. 129(12): 1285-1288. https://doi.org/10.1001/archotol.129.12.1285

24. Farnworth TK, Beals SP, Manwaring KH, Trepeta RW (1993) Comparison of skin necrosis in rats by using a new microneedle electrocautery, standardsize needle electrocautery, and the Shaw hemostatic scalpel. Ann Plast Surg. 31(2):164-167. https://doi.org/10.1097/00000637-199308000-00016

25. Chandra RV, Savitharani B, Reddy AA (2016) Comparing the outcomes of incisions made by Colorado microdissection needle, electrosurgery tip, and surgical blade during periodontal surgery: a randomized controlled trial. J Indian Soc Periodontol. 20(6):616-622. https://doi.org/10.4103/jisp.jisp_27_17

26. Shahzad A (2004) Diathermy and tonsillectomy: criticism of NICE. J R Soc Med. 97(12):610-611; discussion 1. https://doi.org/10.1258/jrsm.97.12.610

27. Magdy EA, Elwany S, El-Daly AS, Abdel-Hadi M, Morshedy MA (2008) Coblation tonsillectomy: a prospective, double-blind, randomised, clinical and histopathological comparison with dissection-ligation, monopolar electrocautery and laser tonsillectomies. J Laryngol Otol. 122(3):282-290. https://doi.org/10.1017/S002221510700093X

28. Shah UK, Dunham B (2007) Coblation for tonsillectomy: an evidence-based review. ORL J Otorhinolaryngol Relat Spec. 69(6):349-357. https://doi.org/1 $0.1159 / 000108367$

29. D'Eredita R, Bozzola L (2009) Molecular resonance vs. coblation tonsillectomy in children. Laryngoscope. 119(10):1897-1901. https://doi. org/10.1002/lary.20210

\section{Publisher's Note}

Springer Nature remains neutral with regard to jurisdictional claims in published maps and institutional affiliations.

\section{Submit your manuscript to a SpringerOpen ${ }^{\circ}$ journal and benefit from:}

- Convenient online submission

- Rigorous peer review

- Open access: articles freely available online

- High visibility within the field

- Retaining the copyright to your article

Submit your next manuscript at $\boldsymbol{\nabla}$ springeropen.com 